\title{
Staphylococcus spp. em camarão minimamente processado refrigerado embalado a vácuo
}

\section{Staphylococcus spp. in minimally processed vacuum packaged refrigerated shrimp}

\author{
Bárbara Camila Firmino Freire ${ }^{1}$; Karoline Mikaelle de Paiva Soares ${ }^{2 *}$; Amanda Sabino de Souza ${ }^{l}$; Antônio Cleyton Arruda \\ de Azevedo Costa ${ }^{1}$; Vilson Alves de Góis ${ }^{3}$
}

Resumo: O objetivo do presente estudo foi avaliar o efeito dos tratamentos com lactato de sódio, ácido cítrico e ácido lático na contagem de Staphylococcus spp. em camarão minimamente processado estocado em refrigeração. Após a coleta das amostras, realizou-se o processamento mínimo utilizando dois tratamentos distintos: o controle e a imersão em solução bioconservante. Em seguida, as mesmas foram embaladas a vácuo e estocadas em refrigeração. Foi realizada a contagem de Staphylococcus spp. a partir do dia zero e repetida em intervalos regulares de 48 horas durante quatro dias. A aplicação dos aditivos resultou em reduções significativas nas contagens de Staphylococcus spp. durante o armazenamento refrigerado, podendo representar uma alternativa viável para aumentar a qualidade e a segurança microbiológica do camarão minimamente processado.

Palavras-chaves: alimento, micro-organismos, bioconservantes, qualidade microbiológica.

Abstract: The aim of this study was to evaluate the effect of treatment with sodium lactate, citric acid and lactic acid in Staphylococcus spp. count in minimally processed shrimp stored in refrigeration. After collecting the samples, the minimum processing was carried out using two different treatments: control and immersion in biopreservative solution. Then, they were vacuum packed and stored under refrigeration. Staphylococcus spp. count was performed from scratch and repeated day at regular intervals of 48 hours over four days. The application of the additives resulted in significant reductions in counts of Staphylococcus spp. during cold storage, which may represent a viable alternative to improve the quality and microbiological safety of fresh-cut shrimp.

Key words: food, micro-organisms, biopreservatives, microbiological quality.

\footnotetext{
*Autor para correspondência

Recebido para publicação em 06/03/2015; aprovado em 03/06/2015

${ }^{1}$ Alunos de graduação em Biotecnologia, Laboratório de Biotecnologia Industrial, Departamento de Ciências Animais, Universidade Federal Rural do SemiÁrido.

${ }^{2}$ Professora de Biotecnologia de Alimentos, Laboratório de Biotecnologia Industrial, Departamento de Ciências Animais, Universidade Federal Rural do SemiÁrido. Av Francisco Mota, s/n, Departamento de Ciências Animais, e-mail: karolinesoares@ufersa.edu.br.

${ }^{3}$ Professor de Tecnologia Agroindustrial, Laboratório de Tecnologia de Alimentos, Departamento de Agrotecnologia e Ciências Sociais, Universidade Federal Rural do Semi-Árido.
} 


\section{INTRODUÇÃO}

A segurança dos alimentos é um importante tema de saúde pública associado à rentabilidade e competitividade do setor alimentício (RANGEL et al., 2014), sendo fundamental, durante o processamento, uma manipulação cuidadosa que visa impedir a contaminação dos alimentos por microorganismos indesejáveis (DE SALES et al., 2013).

Os alimentos minimamente processados, com atributos de alimento fresco, são submetidos a poucos métodos de conservação, e, consequentemente, tais alimentos podem ser susceptíveis à deterioração microbiana e ao crescimento de patógenos (FRANCO et al., 2006). O pescado representa um grupo de alimentos propícios ao crescimento microbiano por possuírem características intrínsecas que favorecem o desenvolvimento de micro-organismos (JAY, 2005). Goes et al. (2011) destacam que dada a susceptibilidade do camarão ao crescimento microbiano e a importância econômica deste crustáceo para economia nacional, o desenvolvimento e aprimoramento de técnicas de processamento visando a obtenção de um produto de qualidade é essencial. Mesmo sendo um produto de relevante importância econômica no Brasil, ainda são poucos métodos de conservação disponíveis (LIMA \& SANTOS, 2014).

Um dos métodos de conservação que vem se destacando nos últimos anos na área alimentícia é a utilização de ácidos orgânicos e seus sais, como ácido lático, lactato de sódio e ácido cítrico que têm demonstrado ação antimicrobiana em carnes e produtos cárneos de diversas espécies de animais (SILVA et al., 2014; FERNANDES et al., 1998; SILVA et al., 2001). O ácido lático e o lactato estão presentes naturalmente no músculo de carnes como o camarão (THERON \& LUES, 2007), sendo formados nos fenômenos bioquímicos pós mortem. O ácido cítrico também é um aditivo considerado natural por ser produzido pelos vegetais ou normalmente por via fermentativa (PENNA, 2001). A elaboração de um camarão minimamente processado tratado com ácido lático, lactato de sódio e ácido cítrico pode aumentar a possibilidade de oferta dos produtos da pesca ao consumidor, o que é um aspecto importante para aumentar o consumo destes produtos no Brasil, conforme destacado por MARENGONI et al. (2009).

A contaminação por micro-organismos patogênicos do gênero Staphylococcus normalmente associa-se aos alimentos manipulados durante o processamento, como minimamente processados, isso porque esses micro-organismos são habitantes usuais da pele, membrana, mucosas, trato respiratório superior e intestino do homem (GERMANO \& GERMANO, 2008), podendo ser transferidos ao alimento durante o seu processamento, podendo seu desenvolvimento ser favorecido pela refrigeração inadequada (FACHINELLO \& CASARIL, 2013).

Neste contexto, o objetivo do presente trabalho foi investigar a influência do tratamento por imersão em solução de lactato de sódio, ácido lático e ácido cítrico na contagem de Staphyloccocus spp. de camarão minimamente processado embalado a vácuo estocado em refrigeração.

\section{MATERIAL E MÉTODOS}

Foram obtidos aproximadamente $4 \mathrm{~kg}$ de camarão marinho (Litopenaeus vannamei) em feira de pescado localizada no município de Mossoró-RN. Após a aquisição, os camarões foram acondicionados em caixas isotérmicas com gelo e transportados ao Laboratório de Biotecnologia Industrial da Universidade Federal Rural do Semi-Árido (UFERSA), onde foram submetidos ao processamento mínimo, com as operações de retirada de cabeça e casca e lavagem superficial com água potável.

Após a obtenção e preparo dos camarões, ocorreu foi realizada a homogeneização dos mesmos, seguida de lavagem com água potável e separação em dois lotes que foram submetidos a tratamentos distintos: TC (Controle) e o TA (Tratamento com solução dos aditivos lactato de sódio 3\%, ácido lático $0,5 \%$ e ácido cítrico $1 \%$ ). As soluções foram preparadas utilizando água destilada previamente esterilizada.

Os camarões do primeiro lote foram acondicionados em bandeja forrada com cinco camadas de papel toalha, previamente esterilizado, em ambos os lados da amostra e em seguida foram dispostos em filmes de baixa permeabilidade ao oxigênio e embalados à vácuo utilizando uma embaladora a vácuo industrial.

As amostras do segundo lote foram tratadas por imersão em solução a $3 \%$ de lactato de sódio, $0,5 \%$ de ácido lático e $1 \%$ de ácido cítrico durante 6 minutos. Após o tempo de imersão, o excesso de solução foi retirado inicialmente através de suspensão em peneira esterilizada e depois em bandejas forradas com papel toalha. Os filés foram embalados a vácuo utilizando filmes de baixa permeabilidade ao oxigênio.

As amostras dos dois tratamentos foram estocadas em duas temperaturas de refrigeração: 4 e $7^{\circ} \mathrm{C}$. Durante $\mathrm{o}$ armazenamento foram realizadas análises microbiológicas para avaliar a qualidade dos camarões. A avaliação foi realizada com três repetições por amostra, a partir do dia zero de estocagem e repetidas em intervalos regulares de 48 horas durante quatro dias.

As contagens de Staphylococcus spp. foram realizadas utilizando a metodologia proposta pela instrução normativa 62/ 2003 do Ministério da Agricultura, Pecuária e Abastecimento (BRASIl, 2003). As análises microbiológicas foram realizadas em câmara de fluxo contínuo. Inicialmente, foram pesados $25 \mathrm{~g}$ da amostra e diluídos em $225 \mathrm{~mL}$ de água peptonada tamponada previamente esterilizada resultando na diluição $10^{-1}$, a partir da qual foram realizadas diluições subsequentes até $10^{-12}$. As amostras foram inoculadas em placas de Petri estéreis com Agar Baird Parker para cultivo em profundidade e incubadas invertidas em estufa bacteriológica a temperatura de $37^{\circ} \mathrm{C}$ por 48 horas.

$\mathrm{O}$ experimento foi conduzido através de delineamento inteiramente casualizado com dois tratamentos e três repetições. Os dados das análises microbiológicas foram submetidos à análise de variância e as médias foram comparadas pelo teste de $\mathrm{T}$ Student ao nível de $5 \%$ de probabilidade. Os resultados foram expressos em $\log _{10}$ $\mathrm{UFC} / \mathrm{g}$.

\section{RESULTADOS E DISCUSSÃO}

A Figura 1 apresenta os resultados obtidos na contagem de Staphylococcus spp. durante o armazenamento refrigerado dos camarões tratados e não tratados. Verifica-se que houve efeito significativo dos tratamentos por imersão em solução de lactato de sódio (3\%), ácido cítrico (1\%) e ácido 
lático $(0,5 \%)$ no dia zero e no segundo dia. No dia zero, a média encontrada no tratamento controle foi de 7,29 $\log _{10} \mathrm{UFC} / \mathrm{g}$, enquanto no tratado foi de $4,10 \log _{10} \mathrm{UFC} / \mathrm{g}$, ou seja, o tratamento resultou em redução de 3,18 ciclos logarítmicos. Aos dois dias de estocagem em refrigeração, verificou-se uma redução de 2,96 ciclos logarítmicos.

Figura 1 - Contagens de Staphylococcus spp. do camarão minimamente processado controle e tratado durante armazenamento refrigerado.

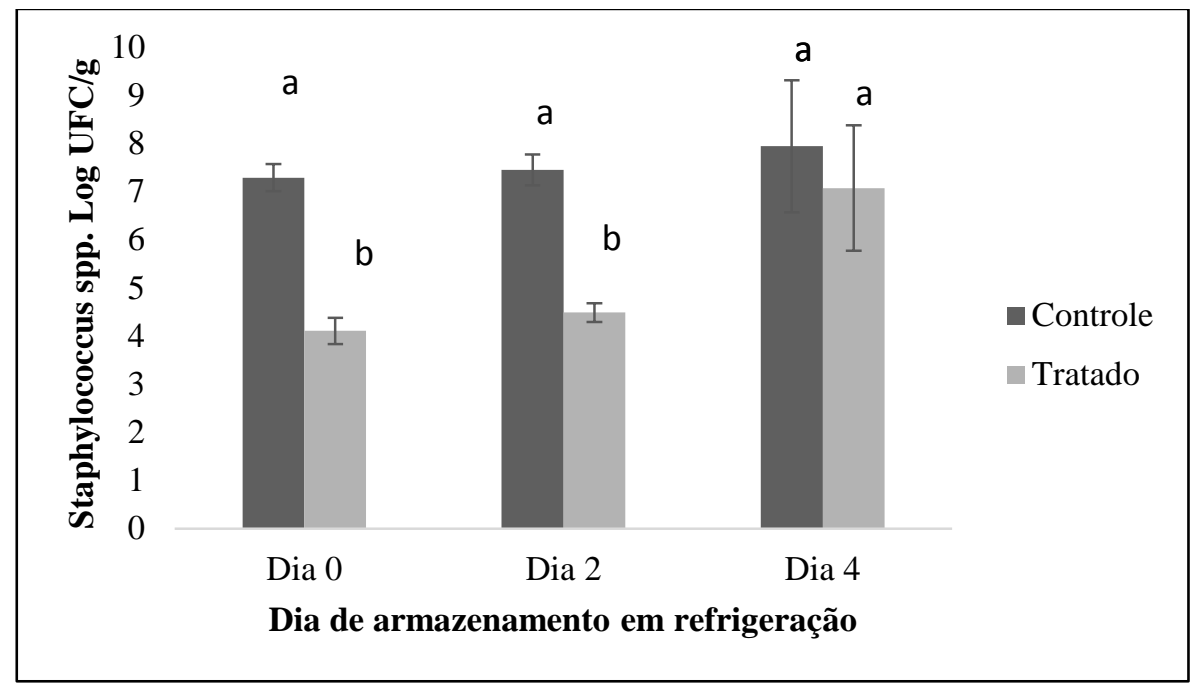

a,b* Letras diferentes em uma mesma coluna em um determinado dia de avaliação indica diferença significativa no teste de T Student ao nível de $5 \%$ de probabilidade.

No quarto dia de armazenamento, apesar da média encontrada para o camarão tratado ser inferior a verificada no controle, não houve diferença estatística entre as mesmas.

A elevada contaminação inicial dos camarões não submetidos aos tratamentos, possivelmente, associa-se falhas durante a manipulação. Segundo Born (2012) o camarão é um produto intensamente manipulado, principalmente o descascado, devido a necessidade de operações como retirada de cefalotórax e carapaça. Pesquisas com camarões frescos vêm evidenciando altos índices de Staphylococcus spp. em camarão fresco (ALBUQUERQUE et al., 2006; NASCIMENTO et al., 1999). Albuquerque et al. (2006), investigando a presença de Staphyloccus aureus em gelo, água, bancadas e vendedores de pescado da feira do Mucuripe, verificaram que $100 \%$ dos vendedores estavam contaminados pelo patógeno. Enquanto Nascimento et al. (1999) verificaram que $40 \%$ do camarão fresco analisado apresentaram contagens de $S$. aureus superiores a $10^{3} \mathrm{UFC} / \mathrm{g}$. Em contrapartida, Costa et al. (2011) verificaram que a maioria das amostras de camarões analisados estava em conformidade com a legislação brasileira (BRASIL, 2001) que preconiza um teor máximo de $S$. aureus de $10^{3} \mathrm{UFC} / \mathrm{g}$ para camarão fresco.

A aplicação do tratamento com lactato de sódio, ácido lático e ácido cítrico proporcionou uma expressiva redução logarítmica nas contagens microbiológicas, que pode ser devida ao efeito antimicrobiano dos ácidos orgânicos e seus sais (HOUTSMA et al., 1993; WIT \& ROMBOUTS, 1990) e constatado por diversos autores em carnes e produtos cárneos de diversas espécies (SILVA et al., 2014; SILVA et al., 2001; VASCONCELOS et al., 2002; KACZMAREKDUSZEK et al., 2008), incluído pescado (FERNANDES et al., 1998; SALLAM, 2007).

A eficiência na redução microbiana detectada no estudo em questão pode ser explicada pelo mecanismo antimicrobiano dos ácidos orgânicos na forma dissociada e não dissociada e, possivelmente, ao efeito sinérgico proporcionado pelo ácido cítrico, reduzindo o pH. Há uma atividade bactericida logo após a sua aplicação e uma ação bacteriostática durante o armazenamento (PRASAI et al., 1992). Este efeito bactericida e uma possível lixiviação de micro-organismos para a água de imersão pode explicar o efeito do tratamento com aditivos logo no dia zero. A ação bacteriostática explica o efeito aos dois dias de armazenamento. No quarto dia, possivelmente, houve uma intensificação dos processos de deterioração e, consequentemente, uma diminuição do efeito dos antimicrobianos estudados.

Segundo Santiago et al. (2013), o consumo de pescado contaminado com bactérias patogênicas é um problema de saúde pública. A aplicação de lactato de sódio, ácido lático e ácido cítrico durante a elaboração do camarão minimamente processado foi uma ferramenta eficiente para incrementar a qualidade e segurança do produto, por reduzir a contagem inicial de bactérias do gênero Staphyloccocus spp, no qual se encontra o $S$. aureus que apresenta risco potencial saúde do consumidor.

\section{CONCLUSÕES}

O uso de lactato de sódio, ácido lático e ácido cítrico resultou em uma eficiente barreira antimicrobiana no dia zero, logo após a aplicação dos tratamentos, indo até o segundo dia de armazenamento em refrigeração, podendo representar uma alternativa viável para aumentar a qualidade e a segurança microbiológica do camarão minimamente processado.

\section{REFERÊNCIAS BIBLIOGRÁFICAS}

ALBUQUERQUE, W. F.; VIEIRA, R. H. S. F.; VIEIRA, G. H. F. 2006. Isolamento de Staphylococcus aureus do gelo, água, bancadas e vendedores de pescado da feira do Mucuripe, Fortaleza, Ceará. Revista Ciência Agronômica, 37(3): 299-303. 
BORN, L. C. Pesquisa de estafilococos coagulase positiva em camarões comercializados em diferentes apresentações. Monografia (Especialização em Produção, Higiene e Tecnologia de Alimentos de Origem Animal), Universidade Federal do Rio Grande do Sul, 2012.

BRASIL. Ministério da Agricultura, Pecuária e Abastecimento. Instrução Normativa $\mathrm{N}^{\circ} 62$, de 26 de agosto de 2003. Oficializa os métodos analíticos oficiais para análises microbiológicas para controle de produtos de origem animal e água. Diário Oficial do Brasil, Brasília, DF, 26 ago. 2003. Seção I. p. 14.

COSTA, R. A.; MOREIRA, B. Á. B.; CARVAlHO, F. C. T. D.; et al. 2011. Staphylococcus coagulase-positiva e enterobactérias em camarão Litopenaeus vannamei comercializado in natura. Revista do Instituto Adolfo Lutz (Impresso), 70(4): 566-571.

De SALES, L. E. M.; ABRANTES, M. R.; De OLIVEIRA, A. R. M.; et. al. 2014. Avaliação da carne suína in natura comercializada em Mossoró-RN. Acta Veterinaria Brasilica, 7(4): 306-310.

FACHINELLO, J. P.; CASARIL, K.B.P.B. Qualidade de presuntos fatiados. 2013. Alimentos e Nutrição. Brazilian Journal Food and Nutrition, 24(3): 333-337.

FERNANDES, C. F.; FLICK, G. J.; COHEN, J.; et al. Role of organic acids during processing to improve quality of channel catfish fillets. 1998. Journal of Food Protection, 61(4): 495-498.

FRANCO, B. D. G.; MARTINS, E. C. P.; ALVES, V. F. Bacteriocinas de bactérias láticas e sua aplicação em produtos cárneos. In: Shimokomaki, M., Olivo, R., Terra, N. N. \& Franco, B. D. G. M. Atualidade em Ciência e Tecnologia de Carnes. São Paulo: Varela, 2006, 236 p.

GERMANO, P. M. L.; GERMANO, P. M. L. Higiene $e$ vigilância sanitária de alimentos. 3. ed. São Paulo: Manole, 2008, 986 p.

GÓES, L. M. N. B.; MENDES, P. P.; MENDES, E. S.; et al. 2011. Uso do metabissulfito de sódio no controle de microorganismos em camarões marinhos Litopenaeus vannamei (Boone, 1931). Acta Scientiarum. Biological Sciences, 28(2): 153-157.

HOUTSMA, P. C.; De WIT, J. C.; ROMBOUTS, F. M. 1993. Minimum inhibitory concentration (MIC) of sodium lactate for pathogens and spoilage organisms occurring in meat products. International Journal of Food Microbiology, 20(4): 247-257.

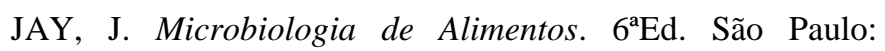
Artmed. 2005, 712p.

KACZMAREK-DUSZEK, J.; BILSKA, A.; KRYSZTOFIAK, K.; et al. 2008. The effect of selected technological additives on improvement of shelf life of ground meat. Acta Scientiarum Polonorum. Technologia Alimentaria, 7(2): 51-61.

LIMA, J. D. F.; SANTOS, T. D. S. 2014. Aspectos econômicos e higiênico-sanitários da comercialização de camarões de água doce em feiras livres de Macapá e Santana, Estado do Amapá. Biota Amazônia, 4(1): 1-8.
MARENGONI, N. G.; POZZA, M. S. D. S.; BRAGA, G. C.; et al. 2009. Caracterização microbiológica, sensorial e centesimal de fishburgers de carne de tilápia mecanicamente separada. Revista Brasileira de Saúde e Produção Animal, 10(1).

NASCIMENTO, A. R.; JESUS, J. R.; PEREIRA, M. S. S. 1999. Pesquisa de Staphylococcus aureus e bactérias aeróbias mesófilas em camarão fresco, sururu e carne moída comercializados em São Luís (MA). Cadernos de Pesquisa, 10(1): 9-18.

PENNA, T. C. V. Produção de ácidos. In: Lima, U. D. A., Aquarone, E., Borzani, W. \& Schmidell, W. Biotecnologia industrial: processos fermentativos e enzimáticos. São Paulo: Edgard Blucher, v. 3, p. 125-154, 2001.

PRASAI, R. K.; ACUFF, G. R.; LUCIA, L. M.; et al. 1992. Microbiological effects of acid decontamination of pork carcasses at various locations in processing. Meat science, 32(4): 413-423.

RANGEL, A. H. do N.; De ARAÚJO, V. M.; De LIMA JÚNIOR, D. M. 2014. Processo de higienização nos equipamentos de ordenha em propriedades leiteiras. Acta Veterinaria Brasilica, 8(2): 107-112.

SALLAM, K. I. Antimicrobial and antioxidant effects of sodium acetate, sodium lactate, and sodium citrate in refrigerated sliced salmon. 2007. Food Control, 18(5): 566-575.

SANTIAGO, J. D. A. S.; ARAÚJO, P. F. R.; SANTIAGO, A. P.; et al. 2013. Bactérias patogênicas relacionadas à ingestão de pescados-revisão. Arquivos de Ciência do Mar, 46(2).

SANTOS, J. S.; OLIVEIRA, M. B. P. P. 2012. Alimentos frescos minimamente processados embalados em atmosfera modificada. Brasilian Journal of Food Technology, 15 (1): 1-14.

SILVA, J. A.; SOARES, L. F.; COSTA, E. L. 2001. Sanitização de carcaças de frango com soluções de ácidos orgânicos comerciais e suco de limão. Revista Tecnologia de Carnes, 3(1): 19-26.

SILVA, R. X. A.; JOSÉ, K. F. C.; FRANCO, R. M.; et al. 2014. Lactato de sódio, nisina e sua combinação na validade comercial da linguiça Toscana embalada a vácuo e estocada a $4^{\circ} \mathrm{C}$. Revista Ciência Rural, 44(4).

THERON, M. M.; LUES, J. F. R. 2007. Organic acids and meat preservation: a review. Food Reviews International, 23(2): 141-158.

VASCONCELOS, E. C.; ZAPATA, J. F. F.; FIGUEIREDO, E. A.; et al. 2002. A microbiota da carcaça e da carne ovina tratada com ácido acético, embalada a vácuo e maturada por 48 dias. Ciência e Tecnologia de Alimentos, 22(3): 272-277.

WIT, J. C.; ROMBOUTS, F. M. Antimicrobial activity of sodium lactate. 1990. Food Microbiology, 7(2): 113-120. 